\title{
A Swollen Head - More than Meets the Eye
}

A healthy 18-year-old Chinese man presented to the emergency department with a 1-day history of mild tender swelling of his crown, forehead and temples (Fig. 1). He was newly enlisted in the military and had recently shaved his head in the past week. He had just completed an outdoor physical training session when he noticed that his forehead had begun to swell progressively. There was no associated fever, itch, lip swelling or shortness of breath. There were no preceding new medications, supplements, contactants or illnesses. Family history was unremarkable.

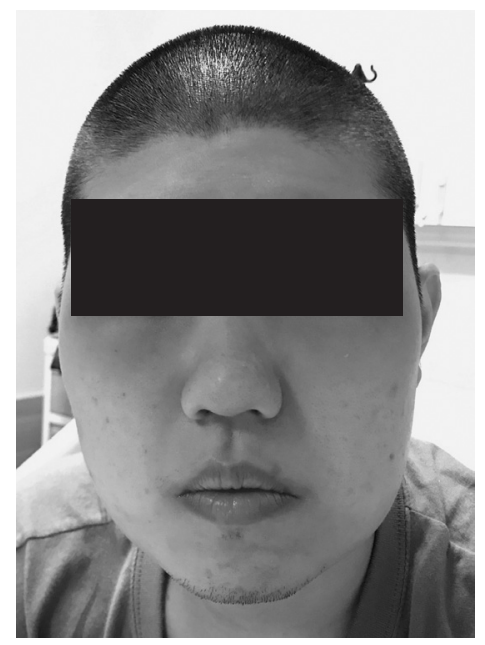

Fig. 1. Clinical examination revealed an erythematous scalp with oedema localised to bilateral frontotemporal regions, extending to the crown. This was associated with erythema and oedema over the sun-exposed areas of his trunk and limbs. There was no urticaria or lip swelling. There were no mouth ulcers, skin erosions, or blisters. There was no stridor and his lungs were clear on auscultation.

What is the diagnosis for his condition?
A. Acute scalp oedema from sunburn
B Allergic contact dermatitis
E. Photoallergic contact dermatitis
F. Phototoxic drug reaction
G. Acute cutaneous lupus erythematosus

The patient was diagnosed with acute scalp oedema secondary to sunburn based on his clinical presentation. There were 6 other military recruits from the same company who presented similarly. All of the recruits were not wearing headgear during their physical training exercise. Out of the 7 recruits, 3 were treated with a short course of prednisolone, while 4 were managed expectantly. During follow-up a week later, resolution of the swelling was noted in all 7 patients (Fig. 2). Sun protection advice was given and there were no further occurrences.

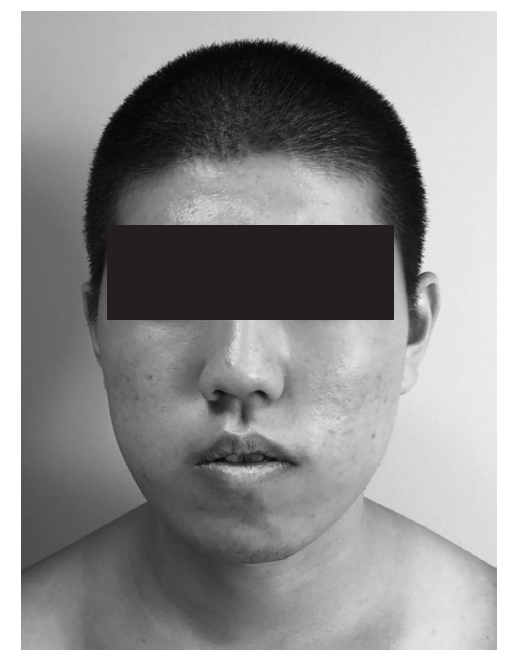

Fig. 2. Resolution of swelling.

\section{Discussion}

Acute scalp oedema secondary to sunburn is a clinical diagnosis. Individuals typically present with the gradual development of a fluctuant boggy mass over the scalp after acute intense sun exposure. Physical examination usually reveals erythema over the sun-exposed areas of the scalp and face, corresponding to the swelling. Patients are well, except for mild skin tenderness. Systemic symptoms should point to an alternative diagnosis.

Differential diagnoses include allergic contact dermatitis and photo-distributed dermatoses. A comprehensive history and examination are paramount. A history of 
contactants should be sought to exclude allergic contact dermatitis and photoallergic contact dermatitis. Recent drug use of non-steroidal anti-inflammatory drugs, antibiotics or retinoids may point towards the possibility of a phototoxic drug reaction instead. A thorough systemic review helps to exclude a primary skin or systemic disease that is photo-aggravated, such as acute cutaneous lupus which may present with systemic symptoms, oral ulcers and blisters.

Sunburn occurs due to the skin reaction secondary to damage by ultraviolet (UV) light exposure. This reaction causes inflammation and oedema due to the increased permeability of blood vessels in the upper dermis. Fluid is trapped between the adherent galea aponeurotica and superficial fascia of the scalp, leading to the appearance of a boggy mass. Symptoms usually occur a few hours after exposure and resolve in 2 to 3 days. Due to the effects of gravity, the swelling is most pronounced in the forehead and bitemporal areas. ${ }^{1}$ Recent head shaving appears to be a risk factor because of the increased sensitivity of the exposed scalp to UV irradiation. ${ }^{2}$ This phenomenon has also been described in unprotected young children exposed to sunlight on hot days. ${ }^{3}$

Given that light sensitivity decreases with repeated sun exposure as a result of photoadaptation, we postulate that graded progressive exposure to sunlight may decrease the risk of sunburn-induced oedema. It is possible that the affected recruits may have had less sun-seeking behaviour compared to their counterparts prior to shaving their scalps, making their newly shaved scalps unacclimated to UV radiation and at increased risk compared to their peers. This may also explain why this phenomenon is not commonly seen in patients with gradually progressive chronic alopecia, whom may, additionally, also be adopting sun protection measures in situations with high UV radiation.

In conclusion, acute scalp oedema secondary to sunburn is not uncommon but is under-recognised. A history of intense and prolonged sun exposure, recently shaven head and evidence of sunburn in a patient with new-onset frontotemporal swelling should prompt suspicion of this diagnosis. Given that majority of Singaporeans do not practise sun safety habits regularly ${ }^{4}$ despite our equatorial climate with high levels of UV radiation, it is important for doctors to be cognisant of this entity to prevent unwarranted investigations. Sun protection awareness (e.g. headgear and sunblock) should be raised among military commanders to reduce incidence of similar cases.

\section{REFERENCES}

1. Verma G, Dave D, Byrne E. Unusual presentation of sunburn. Eur J Emerg Med 2008;15:279-80.

2. Fell M, Pepper S. Scalp oedema after sunburn. BMJ 2013;347:f6703.

3. Shah B, Yavuz S, Tekşam Ö. Scalp edema: don't forget sunburn in children. Turk J Pediatr 2012;54:540-2.

4. Cheong KW, Yew YW, Seow WJ. Sun Exposure and Sun Safety Habits Among Adults in Singapore: A Cross-Sectional Study. Ann Acad Med Singap 2019;48:412-28.

Jamie Xiang Lee Kee, ${ }^{1} M B B S$, Wei Liang Koh, ${ }^{1} M B B S, M R C P$, Wai Leong $\underline{\text { Kok}},{ }^{2}$ MBBS

\footnotetext{
${ }^{1}$ Department of Dermatology, Changi General Hospital, Singapore

${ }^{2}$ Specialist Health Services, Military Medicine Institute, Headquarters Medical Corps, Singapore Armed Forces, Singapore
}

Address for Correspondence: Dr Jamie Xiang Lee Kee, Department of Dermatology, Changi General Hospital, 2 Simei Street 3, Singapore 529889. Email: jamie.kee@mohh.com.sg 